\title{
Bovine papillomatosis: Occurrence and its control by autogenous vaccine
}

\author{
P. Sumitha ${ }^{1 *}$ and K. Sukumar ${ }^{1}$ \\ ${ }^{1}$ Department of Veterinary Microbiology, Veterinary College and Research Institute, Salem - 636112 , \\ Tamil Nadu Veterinary and Animal Sciences University, Tamil Nadu, India

\begin{abstract}
Bovine papillomatosis is a highly spreading viral infection caused by host specific papilloma viruses. It plays an important role in commercial value of animal by affecting the trading and exhibition and also in health condition of the animal may go worse because of secondary bacterial infection. This report aimed to find out occurrence of bovine papillomatosis and to evaluate efficacy of formalin inactivated autovaccine in various breeds of cattle suffered from papillomatosis. An overall of 86 wart samples were collected from various cattle breeds affected with papillomatosis in and around Namakkal district of Tamil Nadu. Breed wise occurrence of papillomatosis was 53.48\%, 37.20\%, 5.81\%, 1.16\%, $\mathbf{1 . 1 6 \%}$ and $\mathbf{1 . 1 6 \%}$ in Holstein-Friesian cross bred, Jersey cross bred, Kangayam, Sindhi, Kangrej and Non-descript respectively. Occurrence of papillomatosis was greater in Holstein-Friesian cross bred (53.4\%). Occurrence in different age group was $38.37 \%, 12.79 \%, 19.16 \%, 15.11 \%$ and $13.95 \%$ in heifers, $1^{\text {st }}$ calving, $2^{\text {nd }}$ calving, $3^{\text {rd }}$ calving and more than four calving respectively. It is more common in heifers $(38.37 \%)$ than adult animals. In the case observation papillomatosis is mainly occurring in eye, teat and udder of the cow. Formalin inactivated autovaccine were prepared and injected at weekly interval showed promising disappearance rate of papillomas within 45 days.
\end{abstract}

Key words: Autogenous vaccine, Bovine papillomatosis, Breed, Occurrence

\section{Highlights}

- Incidence of bovine papillomatosis was common in Holstein-Friesian cross bred cattle (53.48\%) among the various breeds affected.

- Heifers (38.37\%) were most commonly affected by papillomatosis and comparatively least occurrence recorded in adult animals particularly cattle calved more than four times.

- Among the various animals examined papillomatosis lesions were common in eye, udder and teat regions of the cattle.

- Formalin inactivated autogenous vaccine against bovine papillomatosis showed hopeful results and regression occurred within 45 days in most of the animals.

Bovine papillomatosis is a familiar rapidly spreading viral disease of young animals caused by host, site and lesion specific bovine papilloma virus. Fourteen types of bovine papilloma virus identified so far and they are classified into three genera such as Delta, Epsilon and Xi. Every type produces typical lesions in the cattle (Mohammed et al., 2017). Papilloma virus usually spread by direct contact by means of cutaneous abrasions, farm equipment and vectors which carry the virus from infected animals. Papillomatosis happens in 1-12 months of age as the virus exposure to single or multiple parts of affected skin or mucosal epithelium. Predisposing factors associated with the occurrence of papilloma virus are weak immune system, severe sunlight exposure, inheritance, nutritional and hormonal imbalance (Ranjan et al., 2013).

Papilloma viral infection occur as transformation and multiplication of basal cells, leads to wart formation, but most warts are benign and do not proliferate indefinitely. It plays an important role in commercial value by affecting the trading and exhibition quality of the animal. Extensive bovine papillomatosis

*Corresponding Author, E Mail: sumithabvsc@gmail.com 
affect the health condition of the animal especially when the large warts bleed if rubbed or knocked and can result in bacterial infection. Milking processes are disturbed when wart occurred in the teat region of the cow (Radostitis et al., 2007).

Various methods are being used for the therapeutic management of bovine papillomatosis and formalin inactivated vaccine of bovine warts proved to be the best treatment and good prophylaxis against bovine papillomatosis (Suveges and Schmidt, 2003). This effort was made to find out occurrence of bovine papillomatosis in various breeds and age groups of cattle, and its control by inactivated autovaccine.

This study was carried out in the period of 2019-21 employing various breeds and age groups of cattle. An overall of 86 wart samples were collected from cattle affected with papillomatosis in and around Namakkal district of Tamil Nadu for preparation of auto vaccine. Age of the affected cattle and location of papillomatosis lesions were recorded. Samples collection was done by using appropriate precautions to avoid any contamination. All the procedures were undertaken using disposable gloves that were changed at each step. After cleaning the skin with $70 \%$ alcohol, horizontal slices of warts were collected by sectioning parallel on the skin surface using disposable scalpels. It was immediately stored at $4^{\circ} \mathrm{C}$ until further processing.

The inactivated formalin autovaccine was prepared as per the method of (Sreeparvathy et al., 2011) with slight modification. Five grams of collected wart sample was minced and homogenized in normal saline solution using a mortar and pestle along with sterile sand. The mixture was centrifuged at $3500 \mathrm{rpm}$ for 15 mins and supernatant solution was transferred to sterile container, and 0.6 percentage of formaldehyde solution was mixed to the supernatant solution. Formaldehyde added virus containing supernatant solution was kept at $4{ }^{\circ} \mathrm{C}$ for overnight for virus inactivation and stored in refrigerator until further use. Sterility checking was carried out in Nutrient agar and MacConkey agar by streaking drop of virus inactivated autogenous vaccine. After sterility checking $10 \mathrm{~mL}$ of prepared autogenous vaccine was given subcutaneously at weekly interval for 3 weeks at room temperature. Regression of papillomatosis lesion was monitored regularly.

Although bovine papillomatosis is a selflimiting disease, the animals in our study have long lasting multiple papillomas without any sign of regression within months. A total of 86 wart samples were collected from various breeds such as Holstein-Friesian cross, Jersey cross, Kangayam, Kankrej, Sindhi and NonDescript with bovine papillomatosis. Affected animals were from 1 to 7 years of age and 84 samples were from females and two from males.

At the time of examination, the animals had multiple papillomas with size varying from 0.5 to $70 \mathrm{~mm}$ in diameter and disseminated on the ears, nose, head, neck, shoulders, eye lid, back, udder, teat region and vulva. Papilloma lesions were mainly noticed in eye, teat and udder of the cow. The animal was apparently healthy and the warts were strongly attached to the dermis.

Visible lesions and structure of warts clearly aided in the identification and diagnosis of bovine papillomatosis. Clinical examination revealed warts of variable size and shape, smooth/hard, soft/firm, sessile/pedunculated and with/without maggots and bleeding. Grossly, tumour tissue was composed of hyperplastic epidermis supported by thin, inconspicuous dermal stalks.

In the current report, occurrence of papillomatos was greater in Holstein-Friesian cross bred $(54.11 \%)$ and papilloma was more common in heifers $(32.94 \%)$ than adult animals (Table1 and Table 2). In the present report regression of papilloma occurred in about two weeks after treatment and within eight weeks, all warts spontaneously sloughed off and animal showed complete recovery (Fig. 1 and Fig. 2). Recurrences of papillomas were not noticed in treated animals after the six months of treatments. From the current report, it can be concluded that formalin inactivated autovaccine 
Indian Journal of Animal Health, December, 2021

Occurrence and prevention of bovine papillomatosis by autogenous vaccine

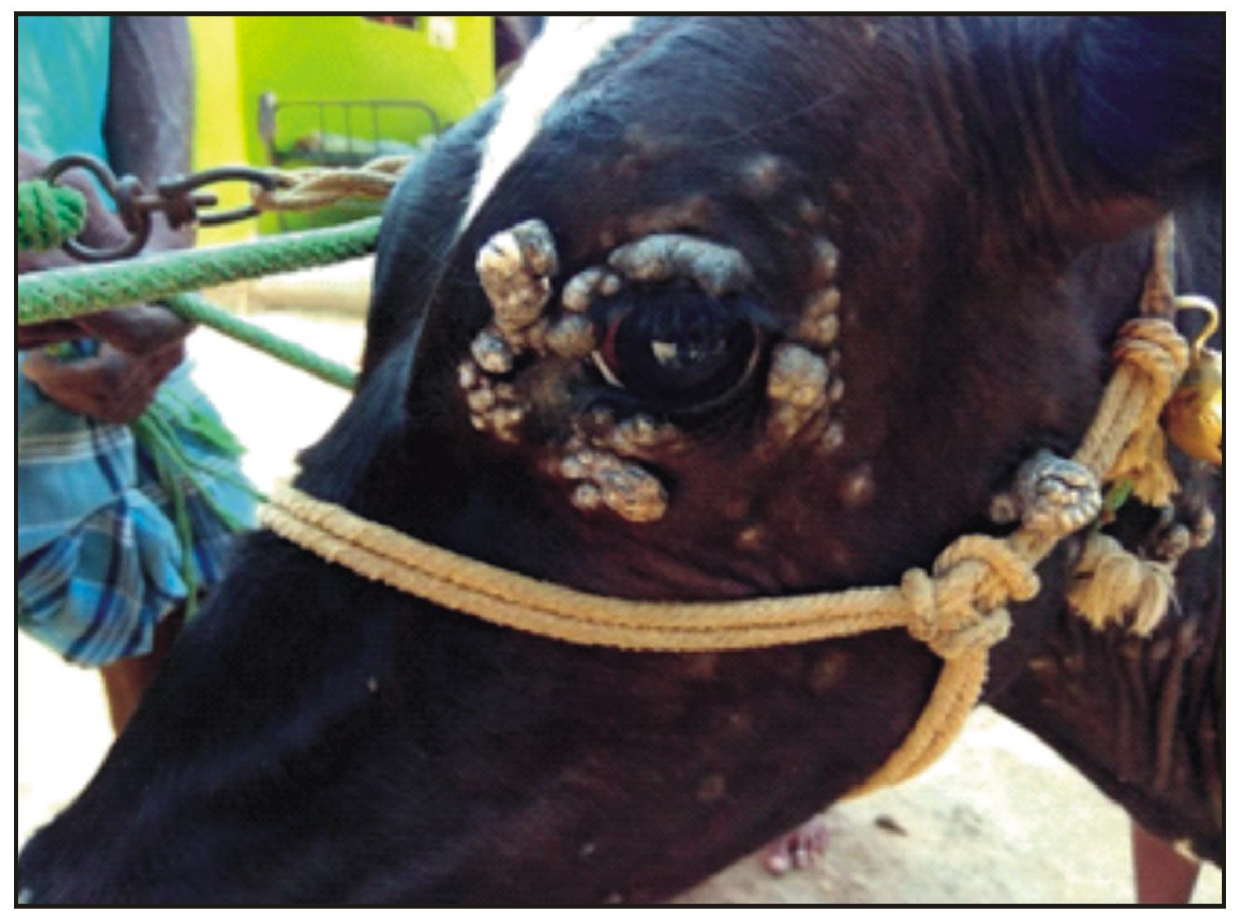

Fig. 1. Cattle papillomatosis: In Holstein Friesian cross bred cow

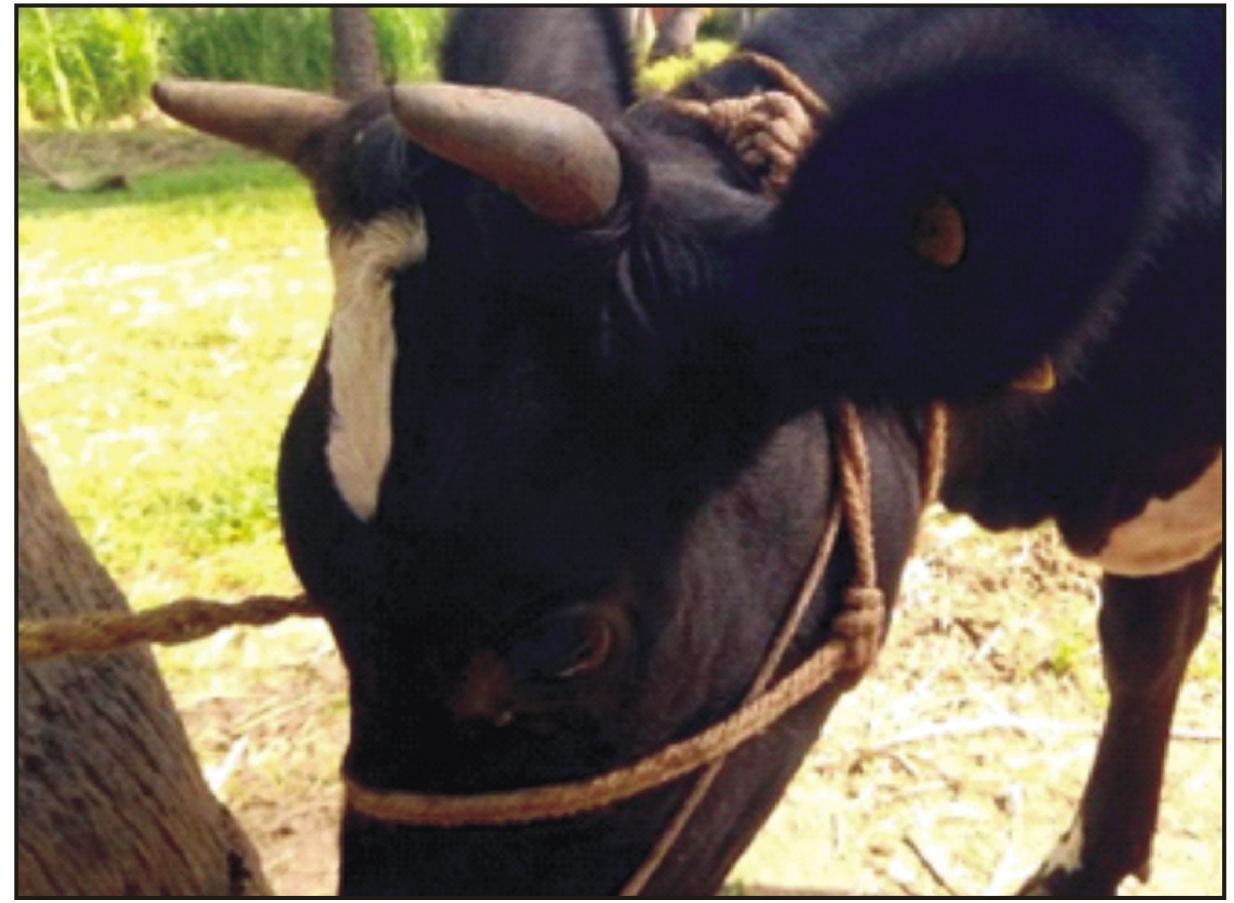

Fig. 2. Cattle papillomatosis: Recovered Holstein Friesian cross bred cow after 2 weeks of autogenous wart vaccine therapy 
Table 1. Breed wise occurrence of cattle papillomatosis

\begin{tabular}{llcc}
\hline Sl.No. & \multicolumn{1}{c}{ Breeds affected } & $\begin{array}{c}\text { Number of samples } \\
\text { collected }\end{array}$ & $\begin{array}{c}\text { Occurrence } \\
(\boldsymbol{\%})\end{array}$ \\
\hline 1 & Holstein Friesian cross bred & 46 & 53.48 \\
2 & Jersey cross bred & 32 & 37.20 \\
3 & Kangayam & 05 & 5.81 \\
4 & Sindhi & 01 & 1.16 \\
5 & Murrah & 01 & 1.16 \\
6 & Kangrej & 01 & 1.16 \\
\hline
\end{tabular}

Table 2. Age wise occurrence of cattle papillomatosis

\begin{tabular}{llcc}
\hline Sl.No. & Age group affected & $\begin{array}{c}\text { Number of samples } \\
\text { collected }\end{array}$ & $\begin{array}{c}\text { Occurrence } \\
(\boldsymbol{\%})\end{array}$ \\
\hline 1 & Heifer $(1-2.5$ years $)$ & 33 & 38.37 \\
2 & $1^{\text {st }}$ Calving $(2.5-3.5$ years $)$ & 11 & 12.79 \\
3 & $2^{\text {nd }}$ Calving $(3.5-4.5$ years $)$ & 16 & 19.16 \\
4 & $3^{\text {rd }}$ Calving $(4.5-5.5$ years $)$ & 13 & 15.11 \\
5 & $>4$ calving $(>5.5$ years $)$ & 12 & 13.95 \\
\hline
\end{tabular}

is effective in therapeutic management of bovine papillomatosis, hence can be applied at field level.

Papillomatosis in bovine is caused by well characterized type 1 to 14 bovine papilloma virus which is highly transmissible cutaneous viral infection of the bovine. Combined infection with many types of this virus occurs most often in the infected animals, which causes variation in the appearance of developing wart lesions (Freitas et al., 2011).

In this report high percentage of papillomatosis occurrence noticed in heifers (less than 2.5 years old). Young animals which are less than one year old and female animals are more susceptible to papilloma infection than male and old animals (Salib and Farghali, 2011). In younger animals, they appear around the eyes, mouth, ears, on the sides of the neck, and on the shoulders.

In this study, co-infection with various types of well characterized bovine papilloma virus was suspected because of incidence of variable size, shape and colour of the lesion. The wart lesions were easily extended to large areas in the animal body; many nodules and big masses were observed which occurred either as hard or soft masses. Delicate wart areas observed to be easily sloughed off, bleed and provide an offensive odour. Weak immune systems, exposure to sunlight, genetic inheritance, nutritional and hormonal disorder are main factor of initiation of papillomatosis (Campo 2002). Severe papillomatosis infection occurs in immunocompromised animals which clearly indicate the association between immunity and development of disease (Borzacchiello, 2007).

Wart lesions have the tendency to slough off spontaneously however sometimes continue to present due to critical environmental and genetic factors (Campo, 2002). The sloughing of papillomas occurs because of cell mediated immunity. Paulik et al. (2001) observed that the lymphocyte blastogenic activity was reduced in bulls affected with prolonged cutaneous papillomatosis. They also reported that the increased lymphocytic activity followed by regression of papillomatosis when autovaccine was used. However in Indian 
market, commercial vaccine against prophylactic or therapeutic management of papillomatosis is not available (Maeda et al., 2007).

Autovaccine used for therapeutic management of papillomatosis is not giving consistent result because this vaccine stimulates the regression of papilloma by stimulating the immune system of the host. The activity of autovaccine against papillomatosis are depends on the type of papilloma virus produces infection, stage of wart lesion, method of wart sample collection, method of autovaccine preparation, vaccine administration and immunity of the host (Sreeparvathy et al., 2011).

In this study, sloughing off papillomas occurred in about 2-8 weeks after treatment and all papilloma spontaneously sloughed off. Animal showed complete recovery without

\section{REFERENCES}

Borzacchiello G, 2007. Bovine Papillomavirus Infections in Animals. Communicating Current Research and Educational Topics and Trends in Applied Microbiology, 673-679

Campo MS, 2002. Animal models of papillomavirus pathogenesis. Virus Res, 89(2): 249-261, doi: 10.1016/s0168-1702(02)00193-4

Freitas AC, Silva MAR, Jesus ALS, Mariz FC and Cordeiro MN, 2011. Recent insights into bovine papillomavirus. African J Microbiol Res, 5(33): 6004-6012, doi: 10.5897/AJMRX11.020

Maeda Y, Shibahara T, Wada Y, Kadota K, Kanno T et al., 2007. An outbreak of teat papillomatosis in cattle caused by bovine papilloma virus (BPV) type 6 and unclassified BPVs. Vet Microbiol, 121(3-4): 242-248, doi: 10.1016/ j.vetmic.2006.12.015

Mohammed AH, Al-Shammari AM, Odishao SM and Yaseen NY, 2017. Molecular epidemiology of bovine papillomatosis and identification of three genotypes in central Iraq. Intervirology, 60(4): 156-164, doi: 10.1159/000486594

Paulik S, Mojzisova J, Levkutova M, Svrcek S, Lesnik recurrences recorded in treated animals after the six months of treatments. It can be concluded that formalin inactivated autogenous vaccine is effective in therapeutic management of bovine papillomatosis hence it can be applied at field level.

Conflict of interest: Authors have no conflict of interest in this study.

Author's contribution: PS: Involved in sample collection, preparation of autogenous wart vaccine and preparation of manuscript. KS: Involved in overall designing of study and assisted in preparation of manuscript.

\section{ACKNOWLEDGEMENT}

The authors would like to acknowledge the facilities rendered by the Tamil Nadu Veterinary and Animal Sciences University, Chennai.

F et al., 2001. Cellular immunity in persistent cutaneous papillomatosis of cattle. Folia Veterinaria, 45(2): 64-67

Radostitis OM, Gay CC, Hinchcliff KW and Constable PD, 2007. Textbook of Veterinary Medicine, 10th edn., 2008 print.; printed by El-sevier, Spain, pp1421-1423

Ranjan R, Ghumman SPS, Bhatt GR and Singh RS, 2013. Efficacy of autogenous vaccine and autohemotherapy in bovine cutaneous papillomatosis. Intas Polivet, 14(2): 411-414

Salib FA and Farghali HA, 2011. Clinical, epidemiological and therapeutic studies on bovine papillomatosis in Northern Oases, Egypt in 2008. Vet World, 4(2): 53-59, doi: 10.5455/ vetworld.2011.53-59

Sreeparvathy M, Harish C and Anuraj KS, 2011. Autogenous vaccination as a treatment method for bovine papillomatosis. J Livestock Sci, 2: 38-40

Suveges T and Schmidt J, 2003. Newer data on the occurrence in Hungary of losses caused by and ways of control of bovine papillomatosis. Magyar Állatorvosok Lapja, 125(2): 83-87

Received - 21.09.2021, Accepted-07.11.2021, Published-01.12.2021

Section Editor: Prof. S. N. Joardar, Associate Editor 